\title{
Internacionalização de saberes e redes acadêmicas: sobre revistas e circulação das ideias na América Latina
}

\author{
Internationalization of knowledge and academic networks: about magazines and the circulation of ideas in \\ Latin America
}

\section{Claudio Maíz}

Consejo Nacional de Investigaciones Científicas y Técnicas de la República Argentina - CONICET - Buenos Aires - Argentina Universidad Nacional de Cuyo - UNCUYO - Mendoza - Argentina

\section{Claudia Lorena Fonseca}

Universidade Federal de Pelotas - UFPel - Pelotas - Rio Grande do Sul - Brasil

\begin{abstract}
$\longrightarrow$
Resumo: Pensar prática das redes é pensar na circulação de ideias. Nesse sentido, como suporte e veículo de transmissão de ideias e configuração de redes, destacamse as revistas, espaço de materialização da prática das redes. O presente estudo pretende abordar as publicações periódicas a partir não apenas de alguns caminhos já percorridos, por estudiosos tais como Beatriz Sarlo, Mabel Moraña, Maria Lúcia Camargo ou Pablo Rocca, a relevância que têm na formação de redes intelectuais, a gravitação política que alcançaram, as controvérsias registradas e outros temas; mas também trabalhar com duas incógnitas: uma delas tem a ver com o momento em que decaem as revistas culturais e em seu lugar se impõem as acadêmicas; a outra, diz respeito à questão formulada recentemente por Regina Crespo sobre se o tempo do protagonismo das publicações periódicas ficou reservado apenas ao século XX. Nesse caso, que outros horizontes se abririam para elas no século XXI, dominado pelas tecnologias da comunicação? Assim sendo, a revista cultural ainda é objeto de estudo para a circulação do novo nos diferentes campos da ciência e humanidades.
\end{abstract}

Palavras-chave: Revistas latino-americanas, redes acadêmicas, internacionalização de saberes.

Abstract: To think of network practice is to think of the circulation of ideas. In this matter, as a support and vehicle for the transmission of ideas and configuration of networks, magazines stand out, as a space for materializing the practice of networks. This study aims to address periodic publications not only from some paths already taken by scholars such as Beatriz Sarlo, Mabel Moraña, Maria Lúcia Camargo or Pablo Rocca, as the relevance they have in the formation of intellectual networks, the political gravitation that reached, the controversies recorded and other themes; but also to work with two unknowns: one of them has to do with the moment in which the cultural magazines decay and in their place the academic ones are imposed; the other concerns the question recently posed by Regina Crespo as to whether the period of protagonism of periodical publications was reserved for the twentieth century. If so, what other horizons open up in the 21 st century, dominated by communication Technologies? Thus, the cultural magazine is still the object of study for the circulation of the new in the different fields of science and humanities.

Keywords: Latin-American magazines, academic networks, internationalization of knowledge. 


\section{Introdução}

O trabalho que tem em vista a cooperação entre investigadores e instituições, sobretudo a cooperação pensada para além das fronteiras nacionais, é não apenas uma tendência que se observa nos meios acadêmicos nos nossos dias, constitui-se mesmo como uma exigência dos nossos tempos. Mesmo que se possa afirmar que não é um fenômeno recente, observa-se que, na atualidade, a cooperação internacional se estabelece como uma prioridade nos meios acadêmicos, ditando os modos de se pensar institucionalmente e orientando as ações e a atividade intelectual de investigadores em todas as áreas do conhecimento. Trata-se de pensar a atuação de atores sociais a partir do objetivo de estabelecimento de relações e vínculos, e muito se tem discutido e buscado pôr em prática, conectando atores distantes geograficamente entre si, via tecnologias ou em presença.

Por esse motivo, talvez não se possa falar em cooperação internacional, ou mais precisamente internacionalização nos meios acadêmicos, sem que tenhamos em mente a ideia de redes, sem considerar o movimento de investigadores no intuito de estabelecer vínculos, conformar redes profissionais. Entendemos que o resultado das ações de troca não pode ficar limitado a um pequeno grupo. Os projetos de cooperação só tem sentido se ultrapassam o âmbito restrito dos grupos de investigação, é mais do que produção, são ações no sentido de integrar e fazer circular as ideias, o que por sua vez fortalece os vínculos.

Nosso trabalho de investigação é fruto de um processo que tem início a partir de ações do trabalho em redes acadêmicas, ao qual se dedicam os autores deste estudo, e que levaram à cooperação, inicialmente, a partir da realização de uma estância pós-doutoral, integrando as duas instituições as quais pertencem os autores, o que por sua vez deu origem a convênios bilaterais, de mobilidade acadêmica, de integração efetiva dos programas de pós-graduação e projetos interinstitucionais a partir dos vínculos que se estabeleceram desde então. Este trabalho tem por objetivo apresentar os resultados encontrados até o presente momento da investigação que empreendemos agora, sob a forma de dois projetos de pesquisa interinstitucionais integrados, liderados pelos autores em suas respectivas instituições, e que têm por objeto de estudo as publicações periódicas latino-americanas.

Pensar as redes intelectuais e acadêmicas é pensar também o processo histórico das relações que se estabelecem entre indivíduos e os grupos aos quais pertencem, e a relação desses grupos alémfronteiras, impulsionados pela necessidade ou desejo de expansão. Pensar as redes intelectuais requer que pensemos as redes de maneira mais ampla, ou seja, como forma de organização social que permite ao indivíduo integrar-se a um grupo a partir de objetivos comuns a todos. Falar em redes é falar em produtividade das relações em sociedade. O modelo não é novo, e já tivemos a oportunidade de dizê-lo, "el nuevo paradigma de la tecnología de la información proporciona la base material para que su expansión cale toda la estructura social" (CASTELLS, 1998, p.549). É a lógica das redes que rege todo o período que vai da expansão marítima à comercial, por exemplo. Hoje, no entanto, à luz da nova revolução tecnológica, a noção se expande de tal forma que se impõe como categoria que explica os fenômenos sociais, a forma de organização da sociedade contemporânea, o que define nossas relações e as trocas que efetuamos. Cada vez mais nos organizamos em torno e a partir de redes. Assim, podemos afirmar que as redes permitem, através de sua trama, a transferência de tópicos culturais, ideias no nosso caso, e preparam os cenários nos quais uma ideia pode triunfar e se impor em um determinado espaço.

Quando pensamos a prática das redes pensamos na circulação de ideias. Nesse sentido, como suporte e veículo de transmissão de ideias e configuração de redes, destacam-se as revistas, objeto de nosso estudo. É nas revistas que a prática das redes se torna bastante material. As revistas se constituem em redes em si mesmas, e o meio privilegiado para a constituição de redes. Portanto, ao 
pensar as revistas a partir da noção de redes, propomos uma abordagem que tem em vista o estudo das Revistas Literárias e Culturais latino-americanas, buscando compreender também como se deu o processo pelo qual gradativamente essas publicações perdem espaço, em termos de representatividade, para as Revistas acadêmicas, ou seja, o processo que acaba por estabelecer as revistas acadêmicas como o espaço privilegiado e legítimo da investigação no campo do literário. Assim sendo, o período compreendido entre os anos 60 e 80 do século passado é especialmente representativo, seja pelo papel que desempenharam as revistas culturais no período, época em que proliferaram e muito significaram em termos de influência nos rumos sociais, políticos e estéticos dessas nações latinoamericanas; seja pelo fato de que é também nesse período que se dá a grande expansão das revistas acadêmicas. Não tendo a pretensão de esgotar o tema, nos dedicamos também a abordar as publicações periódicas a partir da relevância que têm para a formação de redes intelectuais, além de nos dedicarmos a pensar o momento presente das revistas, dominado pelas tecnologias comunicacionais.

\section{Revistas e circulação das ideias na América} Latina

Escreve Gisela Catanzaro sobre o hiato entre natureza e história que "el problema no es tanto cuál es el tipo de relación con los objetos, con el espacio y los cuerpos, es decir, qué tipo de experiencias materiales propone una determinada imagen, obra o representación del pasado, sino qué materialidades se expresan en ella" (2011, p. 40). Assim sendo, se admitirmos que não há nada mais velho que uma revista velha (SARLO, 1993), seria inútil estabelecer os tipos de "experiências materiais", uma vez que perderam toda a força de imediatismo que tinham no momento de sua vigência. Apesar disso, não abandonamos 0 interesse em deixar que as publicações nos falem de seu desuso, esquecimento ou inconsistência devido precisamente às "materialidades que se expressam". Essas materialidades também podem ser pensadas em relação ao que Raymond Williams chamou de "estrutura de sentimentos", uma maneira de tomar o pulso do presente de uma era. É sobre a "cultura vivida", por um lado, e de uma "tradição seletiva", por outro, o primeiro está localizado no passado, mas tendo sido alguma vez presente, o outro é a seleção que fazemos dos fatos do passado do nosso próprio presente. A partir de tais perspectivas, as publicações periódicas ainda podem dar conta dos "materiais" dos presentes que capturaram, sintetizaram ou com os quais não chegaram sequer a se envolver. $A$ experiência vivida, mas suportada pela passagem do tempo, não precisa ser uma circunstância que conspira contra o valor do que se tornou inativo ou fora das agendas de cada presente. Pelo contrário, a "tradição seletiva" opera também no trabalho sobre as revistas e pode nos ajudar a descobrir ainda algumas pistas sobre os rumos da cultura que observamos em nosso presente.

O trabalho que tem as revistas culturais por objeto demanda uma investigação que busque compreender em que consiste esse tipo de publicação, em não poucos aspectos a serem analisados. Patricia Artundo, em estudo de 2010, põe em discussão a natureza dessas publicações, a partir de questões tais como quais podem ser as ferramentas que permitam compreender sua natureza e mecanismos de funcionamento e se é possível pensá-las como objetos autônomos (p.8). O fato é que dificilmente podemos nos debruçar sobre um único aspecto de maneira isolada, já que as revistas são, justamente, o conjunto de todos os aspectos que as constituem. Inclusive a publicidade que veiculam, os editoriais, os aspectos gráficos, tudo fala, e falam em uníssono.

Podemos dizer que são muitas as possibilidades de abordagem, além disso, pode-se dizer ainda que há uma distinção clara entre as pioneiras investigações e o que se observa como tendência na atualidade. Se considerarmos a tradição dos estudos, podemos identificar que estes se debruçam sobre as revistas tomando-as apenas 
como fonte e não como objeto autônomo. É a abordagem mais comum. No entanto, poderíamos dizer que as revistas podem passar de fonte a objeto autônomo, considerando-se o uso que se faça delas. Também não há como deixar de considerar o fato de que "una revista es un instrumento de intervención pública en su próprio presente. Por ese motivo, existiría algo común a todas que sea posible de identificar y aislar para poder analizarlas en tanto objeto?" (ARTUNDO, 2010, p.8).

Mabel Moraña (2003) aponta para dois eixos fundamentais para uma reflexão produtiva sobre não apenas o papel mediador das revistas literárias e culturais da América Latina, mas também, de maneira mais ampla, sobre a função da cultura. O primeiro desses eixos está relacionado à longa tradição reservada à imprensa periódica no continente latinoamericano, incluídas as revistas culturais e as acadêmicas, não importa se independentes ou vinculadas a instituições, responsáveis por "una función principal en el diseño de las culturas nacionales y transnacionales, y en el asentamiento de las bases ideológicas y culturales que conforman la noción de ciudadanía y, más ampliamente, regulan el funcionamiento de la sociedad civil.” (p.67). Quanto ao segundo eixo, Moraña afirma que seria impossível não reconhecer "los múltiples y complejos procesos de resignificación cultural que están teniendo lugar ante nuestros ojos en el contexto de la globalización" (p.67), modificando inexoravelmente o campo cultural, fenômeno que se observa há algumas décadas. Por esse motivo, "dada su objetiva intencionalidad de ser un medio de expresión privilegiado, las revistas permiten visualizar las principales tensiones del campo cultural de un período, ubicándose en la intersección de los proyectos individuales y grupales que muestran las preocupaciones estéticas, políticas y de identidad de la modernidad" (PITA, 2013, p.178), o que explicaria o caráter combativo e questionador dessas publicações, que operam na mediação entre grupos de intelectuais - e suas redes - e o público que desejam atingir, agindo no sentido de formar opinião, seja no âmbito político ou estritamente artístico, se é que podemos, minimamente que seja, desvinculá-los.
Ainda para Moraña, as revistas impulsionaram não apenas a cristalização de novas formas de subjetividade coletiva, mas também a representação de novos atores sociais que, em cena, definem não apenas "una voz través de la cual expresar sus perspectivas y demandas, sino intentando al mismo tiempo crear un publico que funcionara como sistema de control y caja de resonancia de las nuevas agendas" (2003, p.67).

As revistas se caracterizam por seu caráter dinâmico e se fazem à medida mesmo em que as ideias se estão formando, além disso, focam o público, imaginado como "espacio de alineamiento y conflito" (SARLO, 1993, p.9). Por esse motivo, seu tempo é, justamente, o presente, "porque su voluntad es intervenir para modificarlo" (SARLO, 1993, p.9)

"Publiquemos una revista". Centenares de
veces esta frase fue pronunciada por un
intelectual latinoamericano ante otros
intelectuales. Acompañada casi siempre por
dos ideas afines: necesidad y vacío, la frase
inaugura ciclos largos o breves de un impulso
hacia lo público fuertemente marcado por la
tensión voluntarista. "Publiquemos una
revista" quiere decir "una revista es necesaria"
por razones diferentes a la necesidad que los
intelectuales descubren en los libros; se
piensa que la revista hace posible
intervenciones exigidas por la coyuntura,
mientras que los libros juegan habitualmente
su destino en el mediano o el largo plazo.
(SARLO, 1993, p.9).

Publiquemos uma revista, pois, mas para tanto não basta uma iniciativa individual, é necessário que ela seja fruto da colaboração de toda uma rede envolvida nesse objetivo. E não apenas uma rede intelectual, apesar de ser veículo de expressão de uma rede intelectual, e embora não se possa afirmar em todos os casos que elas nascem de um grupo, pois muitas vezes elas próprias conformam uma 'nova' rede, ou pelo menos uma rede mais ampla. Podemos dizer talvez que uma rede conforma uma revista que depois a transforma. Segundo Ignacio Barbeito (2019) é comum que as revistas se convertam em matriz de produção da condição intelectual. Segundo o autor, as revistas podem ser não só "el instrumento de un grupo intelectual para intervenir e incidir en la cultura, sino también el medio 
por el que un escritor o un académico se convirtieron en intelectuales" (p.249). De toda maneira, são muitos os aspectos que podem ser explorados quando se busca investigar em uma determinada revista elementos relativos aos vínculos entre os atores de uma rede, como se organizam no interior desta, ou como a transcendem. Isso significa dizer que podemos ir além da observação das representações políticas, literárias e artísticas de uma rede intelectual ao nos debruçarmos sobre uma determinada revista (PITA, 2013, p.179). Pode-se também, segundo Sarlo (1993) reconstruir-se a relação dos intelectuais com o público a partir dos fracassos e dos êxitos das revistas (p.15), cujo tecido discursivo a autora considera "um laboratório donde se experimentan propuestas estéticas y posiciones ideológicas”. (p.14)

Se a revista rende um tributo ao presente, como afirmou Beatriz Sarlo, também o desafia. Para Pablo Rocca (2004), a revista, "espacio de cruce", é mais que um desafio ao tempo, é um desafio no tempo, com o qual peleia (p.3). "Lo interroga, no puede desprenderse de él, y eso porque más que una tarea individual es un acto colectivo, una puesta en práctica de discurso". (p.3)

Há outra forma possível de se fazer uma revista que seja a "de construir/se cómo grupo para que cada individuo sea, a la vez que sostén, complemento y puesta en crisis del otro, de los otros?", se pergunta Rocca (2004, p.9). Certamente não, e não importa que muitos desses atores circulem entre grupos e redes, culturais ou essencialmente acadêmicas. Constatamos mesmo que, sobretudo na contemporaneidade, quando observamos que as revistas culturais deixaram de ser protagonistas ao serem confrontadas às acadêmicas, boa parte dos teóricos com os quais trabalhamos, brasileiros ou hispano-americanos, militam em duas frentes, ou seja, assim como são muito ativos no âmbito dos debates e da produção literário/cultural, têm uma produção acadêmica muito significativa. Alguns, inclusive, já estão afastados de suas atividades como professores universitários, caso do brasileiro Silviano Santiago, por exemplo. Portanto, cabe a pergunta: porque se dividem nessas duas frentes esses autores? E, como uma questão sempre leva a outras: em que se distinguem e porque muitos ainda insistem nas revistas culturais, que eventualmente lançam, se estas não representam o que representavam; qual a vantagem do conhecimento circular majoritariamente em revistas acadêmicas que poucos leem, quando as revistas culturais cumpriam um papel de maior relevância, que se podia mesurar?

O fato é que não podemos dizer que um tipo de publicação deu lugar à outra, ambas convivem, de certa forma, há muito tempo, talvez não tão em oposição quanto na contemporaneidade. As revistas mais institucionalizadas surgem, a princípio, não necessariamente ligadas a Universidades, embora tenham se estabelecido nestas, visando à divulgação de sua produção acadêmica. Quanto às culturais, servem a grupos e a ideais estéticos ou político/sociais e é inegável sua importância, sobretudo em certos períodos. Sarlo (1993) afirma que deveríamos considerar as revistas como "marcas de los puntos de giro en el espacio cultural del siglo XX" (p.15). Durante o século XIX, por exemplo, "os países latino-americanos contaram com um mercado editorial precário e limitado. Em tal contexto, os jornais e as poucas revistas existentes funcionavam como canais básicos - quando não únicos - para a difusão da criação literária" (CRESPO, 2011, p.100). $\mathrm{Na}$ passagem do século $\mathrm{XIX}$ ao século $\mathrm{XX}$, foram determinantes no que diz respeito ao alcance dos movimentos vanguardistas latino-americanos, a influência dos movimentos libertários e o despontar do nacionalismo cultural, que seriam tema de muitas revistas, panfletos e manifestos (CRESPO, 2011, p.108-109). Nos anos de chumbo, mais que tudo, é o seu posicionamento e seu caráter combativo que se destacam e são fundamentais.

Se nos dedicarmos a recuperar uma trajetória e um nexo determinante dos rumos que tomariam as revistas, no Brasil, por exemplo, podemos dizer que um dos momentos iniciais desse processo é já determinante. Trata-se da publicação da primeira Revista de que se tem notícia, fundamental no que concerne aos rumos da literatura brasileira e ao projeto de formação não apenas de uma literatura, 
mas de uma identidade de nação. Falamos da Revista Niterói, que não surge no Brasil, e sim na França, idealizada e publicada por autores/intelectuais brasileiros que lá viviam. Considerada o marco inicial do Romantismo brasileiro, a Niterói teve apenas dois números publicados, e não foi necessário mais que isso para que cumprisse seu papel como porta voz do projeto nacionalista do grupo que pensava a independência não apenas da nação. Trata-se de uma proposta estética e, a partir desta, também político/social. Também são muitos os que da América Latina de colonização hispânica se dedicam, na França, a colocar em circulação revistas, religando Europa e América.

A Revista Niterói, não foi a única, muitas surgiram depois, igualmente importantes para os rumos formativos/culturais da nação, mas o que se observa é que, de uma maneira geral, muitas das manifestações nesse sentido desde então estão vinculadas não apenas a grupos, mas a instituições. No caso da Niterói, por exemplo, seus integrantes estão vinculados a Instituições e personalidades de destaque no meio intelectual e político do período, tais como o Instituto Histórico e Geográfico.

Porém, o caso mais representativo talvez seja o da Revista Brazileira: jornal de ciências, letras e artes, que circulou em três distintos períodos do século XIX - (1857/1861; 1879/1881; 1895/1899). Em sua terceira fase, a revista está fortemente vinculada à Academia Brasileira de Letras, constituindo-se em veículo por excelência do ideário estético academicista. É em torno da Academia Brasileira de Letras, da Revista Brazileira e de personalidades da época, com propósitos semelhantes, que os literatos da passagem do século se agruparam. Podemos dizer, inclusive, que a revista surge para referendar institucionalmente um fazer literário que se tornaria 0 modelo a ser adotado e seguido por seus membros e todos aqueles que almejassem projeção nos meios literários e intelectuais do país. Vejamos, por exemplo, seu primeiro editorial, já bem definidor de propósitos.
[...] republicana, mas profundamente liberal, [a Revista Brazileira] aceita e admitte todas as controvérsias que não se achem em completo antagonismo com a inspiração da sua direcção. Em Politica, em Philosophia, em Arte, não pertence a nenhum partido, a nenhum systema, a nenhuma escola. Pretende ser simplesmente uma tribuna onde todos os que tenham alguma cousa que dizer e saibam dizei-a, possam livremente manifestar-se (EDITORIAL, 1895, p. 3).

Perceba-se que, apesar do propósito abrangente e democrático saltar aos olhos, contraditoriamente, a revista irá admitir todas as controvérsias "que não se achem em completo antagonismo com a inspiração da sua direção", e "sua direção" está vincula à Academia Brasileira de Letras e aos princípios ideológicos e estéticos por esta propagados. Manifestações de membros da academia são significativas no que diz respeito a esse aspecto e são exemplares quanto ao que se considerava o compromisso do homem de letras de então. Vejamos o que diz Machado de Assis, fundador e principal figura literária e intelectual de então, para ele, a função da Academia é aristocrática, para ele, a Academia Brasileira de Letras tem de ser o que são as associações análogas: "uma torre de marfim, onde se acolham espíritos literários, com a única preocupação literária [...] Homens daqui podem escrever páginas de história, mas a história faz-se lá fora”. (MACHADO DE ASSIS, 1897, p. 1).

Não é diferente a situação na América latina de colonização hispânica, as revistas sempre foram veículo de estéticas e de pontos de vista manifestos. O fato é que, a partir de um determinado momento dessa trajetória, busca-se cada vez mais que representem os anseios e influam em uma parcela mais significativa de pessoas, que sejam um espaço democrático de manifestação, ou seja, é desejável e se incentiva que a intelectualidade deixe a torre de marfim, posicionando-se na rua, digamos. No entanto, na trajetória que se pode reconstituir, percebemos que, de certa forma, há um movimento de regresso ao seio institucional. A esse respeito é paradigmático o caso do debate que se estabelece em fins da década de 70, reproduzido no número 9 da Revista José. Literatura, crítica \& arte, em dezembro 
de 1977, em que se discutem não apenas os rumos da Revista José, mas das publicações com propósitos semelhantes, mesmo que com pontos de vista divergentes, que surgem e se extinguem em profusão nesse período. Participam do debate que, reproduzido na revista, tem como título -“José no espelho", os escritores Silviano Santiago, Ferreira Gullar, Luiza Lobo e Geraldo Carneiro, os quais se juntam ao conselho editorial da revista, formado por Luiz Costa Lima, Gastão de Holanda, Jorge Wanderley e Sebastião Uchoa Leite. O debate não é conclusivo, de fato, não se chega sequer a um consenso entre tantas opiniões divergentes.

Chamamos a atenção aqui para o que se pretende sejam os problemas a serem solucionados: a permanência das publicações; o desejo de que se constituam essas publicações em porta-vozes de investigadores não pertencentes a um grupo homogêneo; e a neutralidade politica, ou no máximo, o acolhimento de múltiplos pontos de vista, mesmo que conflitantes. Ora, isso nos remete ao primeiro editorial da Revista Brazileira, e assim como naquele editorial, há contradições. Evidencia-se aqui um surpreendente desejo de institucionalização das revistas. Ou de retorno à Instituição. Certamente os tempos são outros. Não podemos ignorar as determinações do mercado e a massificação da cultura - a cisão entre cultura popular e cultura erudita, a impossibilidade de competir com as revistas mais humorísticas, digamos, e/ou satíricas, e com a mídia televisiva, ou seja, o acesso ao entretenimento travestido de cultura está facilitado e as revistas literárias nos moldes do que se tinha começam a ser vistas como "coisa pouco digerível", produto de consumo para intelectuais, não para o povo. Em suma, "não vende".

No entanto, a lógica do lucro nunca foi compatível com a essência desse tipo de publicação. Em geral, aquelas que visaram ao lucro sucumbiram, vide a Revista do Brasil que pertenceu a Monteiro Lobato, por exemplo. Esse tipo de publicação, evidentemente, não vende. Vendia um pouco mais quando não havia outras opções em termos de atualização cultural, e quando o conhecimento, o livro, a arte estavam acessíveis apenas a uma elite cultural. Nesse desmembramento cultura/conhecimento/informação, o ensaio literário se refugia nas revistas acadêmicas, que além de serem patrocinadas pelas instituições, chegam "a quem quer consumi-las". O problema da Revista José naquele momento não é apenas o problema da Revista José, o fato é que o debate que promovem pode ser visto como um debate acerca do impasse que estão vivendo as publicações do gênero, naquele contexto específico. Além disso, não há mais "movimentos literários" nos moldes do que antes havia, as revistas podem servir a tendências, mas não mais como veículo de um movimento estável e identificável como "A" tendência. Há que se considerar ainda que depois de um período de ausência de informação e de alienação do povo em geral, as consequências disso se fazem sentir nas "necessidades", nas demandas do povo despolitizado que agora não quer uma revista cultural, mas sim o folhetim televisivo. Esse é o cenário não apenas no Brasil, mas na América Latina como um todo.

Nessa trajetória da instituição para a rua e da rua de volta à instituição, a vertente cultural/literária não desaparece, mas perde força de representatividade. Além disso, com as transformações sociais, essas publicações acabam por ser menos rua do que seria desejado, e se elitizam tanto quanto as publicações acadêmicas, perdendo o caráter vanguardista-arte além do caráter questionador. Uma nova configuração do cenário também determina uma mudança de perspectiva dos estudos que têm por objeto as publicações periódicas. No entanto, se podemos identificar um movimento no sentido de privilegiar "el universo de relaciones sociales en las que las revistas son producidas a la vez que los contextos intelectuales de sus intervenciones" (GRISENDI, 2019, p.254), em detrimento do conteúdo de seus textos e seus efeitos, mesmo que não se perca de vista a dimensão textual, podemos dizer que esse movimento é ainda tímido naquilo no que concerne ao espectro mais amplo das publicações periódicas. Praticamente não estão contempladas as revistas acadêmicas, por exemplo, 
nos questionamentos que se fazem. Talvez porque a princípio se vejam dissociadas as formas, as discussões que se fazem em torno à suposta decadência das revistas culturais em raras ocasiões põem em evidência a relação entre elas. Sequer se cogita a possibilidade de que a perda de protagonismo das revistas culturais esteja associada à ascensão das revistas institucionais. Não são muitos os estudos a abordar esse aspecto, apesar de se terem multiplicado nas últimas décadas os horizontes de investigação na pesquisa sobre revistas (GRISENDI, 2019, p.254). "Este deslizamiento metodológico, sin embargo, no siempre resultó acompañado por una indagación ampliada de publicaciones periódicas de perfil institucional (revistas universitarias) u orientadas al público masivo (revistas de periodismo de masas)", aponta Ezequiel Grisendi (2019, p.254). No que estamos de acordo com o autor argentino.

Uma revista se apresenta como um objeto múltiplo, afirma Ignácio Barbeito, em um interessante conversatório dedicado o tema, organizado pelo Centro de Investigaciones de la Facultad de Filosofía y Humanidades de la Universidad Nacional de Córdoba, em novembro de 2018, depois publicado. Para o autor, cada revista, a que nos referimos pelo título, está constituída na verdade por várias revistas, por vários números do que consideramos uma mesma revista (2019, p. 247). Assim sendo, “¿qué otorga a este conjunto, temporalmente diferenciado y, a veces interrumpido y vuelto a resurgir tras unos años, una unidad de objeto? [...] ¿es posible, de un número a otro, postular la identidad del objeto?" (BARBEITO, 2019, p.247).

Objeto múltiplo, portanto, as revistas ainda se caracterizam por significar de forma distinta, se consideramos não apenas seu período circulação, mas também sua natureza e missão. Considerando os significados contemporâneos do termo, e destacando o caráter huidizo das revistas, Maria Lucia Camargo (2003) aponta para três categorias básicas no que se refere a esse tipo de publicação, a saber: periódicos institucionais; periódicos independentes e de tiragem reduzida; periódicos de ampla circulação (p.). Já Rocca (2004) propõe outra classificação, tributária, segundo o autor, à de Gramsci. Para o estudioso uruguaio, as revistas podem ser classificadas em três categorias: as revistas institucionais, ou acadêmicas, protegidas ou financiadas por uma instituição, em geral uma Universidade; as revistas propriamente culturais, ou de intervenção, "que se inscriben en el debate por cuenta propia, con escasas posibilidades de supervivencia, habitualmente con débiles apoyos 0 contrapesos, a veces con la expresa voluntad de ser marginal, de trabajar desde la periferia contra un centro" (2004, p.6); e um terceiro caso, que seriam as revistas caracterizadas pela hibridação, nos moldes de Casa de las Americas, por exemplo, embora destaque que esse tipo hoje tenha cedido lugar definitivamente às revistas científicas, que se apresentam com normas referenciais rígidas, reproduzindo um esquemas de trabalho intelectual que obedecem muitas vezes a determinadas tendências "acadêmicas" do período e "a menudo enemistado con la prosa "galana", la claridad expositiva y, no está de más señalarlo, hasta con el dominio de una lengua estándar básica para el establecimiento de la comunicación." (ROCCA, 2004, p.8). Observamos que, se a classificação de Camargo não contempla os periódicos de caráter híbrido, a de Rocca exclui os periódicos de ampla circulação, citados pela estudiosa brasileira, que se constituiriam certamente na ampla variedade de periódicos de natureza mais comercial, digamos, que podemos encontrar nas bancas de jornais e revistas. Observamos também que nenhuma das classificações propostas contempla as revistas de circulação virtual, híbridas por natureza, obviamente não nos moldes do que propõe Rocca, mas essencialmente híbridas mesmo assim.

Considerando a situação que se evidencia nos nossos dias no que concerne ao papel desempenhado pelas revistas culturais na produção da condição de intelectual, afirma Barbeito (2019) que este não é representativo. Compartilhamos da opinião do autor, para quem, ainda, a noção de revista político-cultural sobrevive como espectro de um 
campo cultural que já não é o nosso, e mais, considera que essa categoria, depois da segunda metade dos anos 90 já não é operativa. De acordo com o autor argentino,

Si la revista político cultural otorgaba a la palabra "intelectual" una dimensión pública, las que sólo por comodidad y economía de expresión podrían llamarse hoy revistas político culturales adquieren casi el carácter de ediciones privadas. La producción digitalizada, por caso, asegura la posibilidad de una viralización comunicacional prescindiendo del requerimiento de atender al marco editorial de la publicación, algo que es particularmente relevante en el caso de material impreso. (2019, p.249).

Segundo Sarlo (1993), uma história que tivesse por objeto as modificações institucionais "de los lugares que ocupa el discurso literario y, sobre todo, que focalizara en los conflictos ideológicos y estéticos, puede hacerse sobre la base de las revistas [culturais]" (p.11). Poderíamos dizer o mesmo a respeito das acadêmicas? Observamos uma atenção sempre renovada no que diz respeito à investigação que tem por objeto as revistas culturais, mas e sobre a função das revistas acadêmicas nesses processos, seria essa categoria de publicação periódica apenas um espaço para a difusão da ciência, a serviço institucional? Como pensar dessa forma se, sabemos, estas se converteram no principal veículo de difusão e circulação de ideias e conhecimento? Elas assumem o protagonismo, isso é certo, mas é possível analisar a sintaxe de uma revista acadêmica da mesma forma que assim o fazemos com as culturais?

\section{Ganhos e perdas}

Talvez fosse lícito afirmar que muito se perdeu nesse caminho que vai das revistas culturais às acadêmicas, em termos de representatividade, embora seja evidente que estas se multiplicam diariamente, atingindo supostamente um público maior, devido à facilidade propiciada pelas tecnologias, sem contar o advento do acesso aberto. Supostamente maior, diríamos, se consideramos apenas a possibilidade virtual de alcance, o que não se concretiza de fato em consumo, visto que se trata de um público restrito o que busca esse tipo de publicação. Além disso, outras questões se impõem quando nos dedicamos à análise mais aprofundada do objeto revista, neste caso em sua modalidade virtual. Algumas dessas questões dizem respeito a sua forma. Barbeito (2019), por exemplo, questiona: "¿Cómo modifica internet la naturaleza de una publicación aun cuando la identidad nominativa nos haga creer que también estamos ante una "revista"?" ou ainda: "¿Qué decir de las revistas digitales, cuando internet se despliega siempre en un presente perpetuo?" (p.248). Como se pode perceber, as questões que surgem se multiplicam na mesma proporção que se multiplicam as publicações acadêmicas as quais temos acesso virtualmente. E muito resta ainda por se resolver no que diz respeito ao tema.

Para Rocca (2004), o que se ganhou eliminando a nebulosidade e a fatiga da improvisação se perdeu em criatividade de escritura "que sólo refulge en quienes no dejan de pensar la escritura como una forma al servicio de un objeto teórico o de un corpus temático dado, ya sea canónicamente literario o "cultural'” (p.8). A perda atingiria ainda mais as revistas culturais ditas de intervenção, aquelas que antes 'todo el mundo llamaba 'literarias' sin ningún tipo de complejos" (p.8), segundo o autor, que aponta como principal motivo para esta perda a ausência do que ele chama de função fática entre produtores e receptores, situação que as revistas eletrônicas não conseguiram resolver satisfatoriamente (p.8). Se as tecnologias proporcionam infinitas possibilidades de acesso, não apenas à informação, mas também ao outro, e contatos, que estão virtualmente disponíveis no instante mesmo em que os buscamos, ampliando a trama das redes intelectuais, acadêmicas e pessoais que tecemos, ao mesmo tempo, ao eliminar o contato direto entre os agentes, estas mesmas tecnologias impedem que "se generen los debates públicos y las relaciones íntimas necesarias con la producción cultural específica, que siempre requiere un mínimo tiempo de germinación" (ROCCA, 2004, p.8). Essa seria provavelmente a principal razão pela 
qual se tenha tornado instável a noção mesma de revista.

Mabel Moraña (2003) afirma que, se a representação, tanto simbólica como política, "es ya un campo de batalla por la hegemonía de los discursos, el mercado traduce esas tensiones a niveles materiales que decretan la continuidad 0 desaparición de las publicaciones que compiten por el consumidor cultural." (p.69) E acrescenta, ainda, que os processos de globalização sem dúvida acentuaram esses fenômenos "complicándolos en la medida en que agudizan desafíos que la modernidad solo insinuara en la primera mitad del siglo $\mathrm{XX}$, en distintos grados, en las diversas partes del continente" (p.69) Segundo a autora, isso se deve, entre outros motivos, ao fato de que,

\begin{abstract}
la globalización necesita lenguajes capaces de crear puentes culturales y facilitar la traductibilidad de códigos y parámetros valorativos. Junto a la variada gama de lenguajes y soportes visuales, electrónicos, y sígnicos, las lenguas se sitúan en una competencia no solo enfrentada a las interacciones multimediaticas, sino también colocadas ante nuevos conflictos y luchas de poder. Sería ingenuo pensar que la simultaneidad de tiempos y de espacios que la revolución electrónica ha creado a nivel planetario crea solamente flujos de integración y de intercambio que democratizan, sin otras consecuencias, el espacio cultural transnacionalizado. Más bien, resulta imprescindible enfocar la realidad de nuevas o reforzadas hegemonías que atraviesan el campo cultural globalizado en un impulso por capitalizar los procesos de resignificación discursiva y gestionar las dinámicas de hibridación que se desarrollan en distintos contextos. (p.69).
\end{abstract}

Constatadas as particularidades das publicações periódicas conforme se apresentam hoje, resta uma questão a ser posta: podemos aplicar a noção de redes intelectuais às revistas acadêmicas, como estas se apresentam hoje, da mesma maneira que aplicamos essa noção às revistas culturais? Até que ponto as revistas acadêmicas disseminam o pensamento de um grupo/rede específico e não apenas o de um indivíduo, que certamente integra redes, mas que se manifesta em seu próprio nome? Podemos observar as tramas culturais de um período a partir do estudo das revistas acadêmicas, isso é certo, mas podemos dizer que esses estudos contemplariam a totalidade do fenômeno? Talvez possamos pensar que o componente intertextual do conteúdo manifesto em um artigo científico, o diálogo do autor com suas referências, se constitua em uma rede intelectual em alguma medida. Mesmo porque muitos são contemporâneos e estão em contato direto, virtual ou não. Mas podemos dizer que, de fato, tem força de grupo? Pensamos no trabalho de um editor ao selecionar o que será publicado, na conformação dos comitês editoriais, entre outros aspectos, e podemos dizer que se constata certa unidade nesse pensamento, frágil é verdade, mas detectável eventualmente em algumas publicações com políticas editorias pensadas justamente para que a revista traduza um ponto de vista determinado, mas isso não parece suficiente. Não parecem oferecer aos participantes os recursos materiais e simbólicos que Ihes permitiriam atuar de forma destacada no espaço público e político da sociedade.

\section{Considerações finais}

As revistas acadêmicas sistematizam hoje o estudo da literatura, mas não o fazer literário. Revistas acadêmicas e revistas culturais são objetos, ou fenômenos, distintos, embora ensaístas possam publicar em ambas, mesmo levando em conta que os que mais se dividem entre elas sejam os ensaístasliteratos. O problema talvez seja a energia dispensada às acadêmicas, como se apenas essas tivessem valor e pudessem ser consideradas naquilo que veiculam. Estes periódicos continuam o trabalho de servir a instituições, sistematizando e valorando agora não mais exatamente a literatura, mas o estudo da literatura, atribuindo validade ao que veiculam, ao mesmo tempo em que se desacredita as revistas culturais e deixa-se de proporcionar viabilidade a estas que, quando surgem, é em um empenho muitas vezes individual, desaparecendo quando não se resiste mais ou a publicação já serviu a um propósito. No entanto, não seria essa, desde sempre, a característica dessa espécie de publicação? O grande problema seria a volta à torre de marfim, esse é o 
cuidado que se deveria ter com a institucionalização. Institucionalizadas, as revistas perdem uma de suas principais funções, que é a de apontar a diversidade e o novo, o que continua a ser função das revistas culturais, que resistem e continuam surgindo, mesmo que tenham perdido força e crédito ao serem confrontadas com as acadêmicas.

O que se perde nesse processo que vai das Revistas culturais às Revistas estritamente acadêmicas diríamos que é, sobretudo, o caráter dinâmico e contestador, o favorecimento da reflexão social/cultural/politica, a perda de um privilegiado veículo de explicitação de ideias e pontos de vista; se perde veemência, a voz que, em sendo necessário é grito, o poder de coletivo ativo, a possibilidade e o poder de câmbio, de denúncia e de transformação, a multiplicidade, o lúdico, a interatividade, poder de fogo e vida. As ressuscitadas revistas culturais e literárias hoje não cumprem com esse objetivo, embora sejam dirigidas a esse público especializado. $E$ as acadêmicas tampouco são tão duráveis naquilo que difundem, apenas permanecem no tempo como veículo do pensamento acadêmico. O periódico nesse caso ganha longevidade, mas não são longevos, necessariamente, o conteúdo e as ideias que veiculam.

Segundo Fernanda Beigel (2003),

\begin{abstract}
Algunas revistas culturales cumplen una función aglutinante dentro del campo intelectual y eso las convierte en referencia obligada de la Historia de las Ideas de un pueblo. Muchas de éstas se institucionalizan y perduran durante décadas. Otras representan grupos que elaboran una línea ideológica tan coherente como radicalizada y tienden a esfumarse en poco tiempo. En el caso de las revistas de vanguardia, tienen la particularidad de que se trata de emprendimientos que estuvieron atados - como el fenómeno vanguardista mismo - a coyunturas históricas complejas, pero bien recortadas. (p.106).
\end{abstract}

Conforme podemos perceber, não se trata apenas de carência de recursos e apoio o problema da dificuldade de permanência no tempo de uma publicação cultural, é também o próprio caráter dinâmico do objeto Revista, efêmero como a própria ideia de momento, que remete à imprensa, periódico, atualidade, que servem a um propósito, a um grupo reunido em torno de uma ideia ou objetivo comum. Mentalidades, tempos e pessoas mudam, a ideia se aperfeiçoa, ou se mostra inviável, ou é substituída por uma melhor, ou se reinventa, e assim os periódicos culturais. É preciso aceitar a efemeridade dessas publicações, e suas novas configurações, estabelecer-se pode ser um indicador de estagnação e engessamento; ao se institucionalizarem, também, se tornam dependentes da instituição que as acolhe, de certa forma tornam-se reféns dessa instituição. Hoje, a maior parte dessas publicações assume seu papel acadêmico e o de divulgação de sua produção sem que se vejam como a acomodação do pensamento vivo e ativo dos intelectuais de então.

Os objetivos hoje são distintos, mas há aqueles autores que atuam nas duas frentes, não sem certa nostalgia do que se tinha, posto que essa diluição custou um pouco caro: as revistas culturais não são mais o que eram, e nem as revistas acadêmicas supriram as carências que estas deixaram. Nenhuma das duas vertentes tem hoje tanto poder de impacto na sociedade, como já tiveram as revistas culturais, e ambas estão elitizadas, virtualmente acessíveis a um grande público, mas não acessíveis de fato. Obviamente, não é o caso de se ir contra a divulgação do pensamento científico e a produção acadêmica, muito pelo contrário, esse movimento de certa forma é também um propósito, embora limitado, muitas vezes. Em todo o caso, as revistas acadêmicas não surgiram depois das revistas culturais, periódicos acadêmicos já existiam desde que as Universidades se estabelecem como o espaço por excelência do conhecimento. Não existiam em número elevado, mas podemos dizer que, desde pelo menos os anos 50 do século passado, surgem e vão ocupando um espaço, coexistindo com as Revistas culturais, tornando-se o veículo de difusão do pensamento de intelectuais agora ligados a cátedras universitárias. Algumas delas, inclusive, são publicadas até 0 presente. $O$ fato é que 0 deslocamento dos intelectuais para o ensino em universidades é também determinante desse fenômeno de cisão entre Revistas Culturais e 
Acadêmicas. Podemos constatar que não são poucos os fatores a serem considerados na análise do fenômeno.

Portanto, no que diz respeito ao tema do qual nos ocupamos, a transição da circulação do pensamento das revistas culturais às acadêmicas, podemos dizer que o atual momento é de coexistência das duas formas, e de suas variantes. No entanto, evidencia-se que as acadêmicas são, hoje, o espaço privilegiado de divulgação e circulação do pensamento intelectual. Em tempos de acesso aberto, as revistas acadêmicas se estabelecem como ferramenta essencial a serviço da investigação científica. Quanto às revistas culturais, estas também se beneficiam das possibilidades do mundo virtual, em uma capacidade de reinventar-se que é mesmo uma de suas principais características. E esse processo, certamente não é exclusivo de um, ou de alguns, sistemas literários ou culturais, é um fenômeno tão amplo quanto abrangente, e afeta a circulação das ideias em escala global, como não poderia deixar de ser considerando-se os suportes disponíveis e o alcance proporcionado pela expansão digital e as novas tecnologias.

\section{Referências}

ALtAMIRANO, (dir.). Historia intelectual en América Latina. Tomo II, Buenos Aires: Editorial Katz, 2010.

Intelectuales. Notas de investigación sobre una tribu inquieta. Buenos Aires: Siglo XXI, 2013.

ARTUNDO, Patricia. Reflexiones en torno a un nuevo objeto de estudio: las revistas. In: IX Congreso Argentino de Hispanistas. Asociación Argentina de Hispanistas, La Plata, 2010, p. 1-16. Disponível em:

http://www.memoria.fahce.unlp.edu.ar/trab_evento s/ev.1028/ev.1028.pdf. Acesso em: 26/10/18.

BEIGEL, Fernanda. Las revistas culturales como documentos de la historia latinoamericana. In: Utopía y praxis latinoamericana, a. 8, n. 20, marzo, 2003, p. 105-115. Maracaibo: Universidad del Zulia. Disponível em: http://www.redalyc.org/articulo.oa?id=27902007. Acesso em: 26/10/18.

CAMARGO, Maria Lucia. Sobre revistas, periódicos e qualis tais, In: Travessia, Florianópolis, Universidade Federal de Santa Catarina, Curso de
Pós-Graduação em Literatura, 2o Semestre de 2003, p. 21-40. Disponível em: https://periodicos.ufsc.br/index.php/Outra/article/vi ew/13089/12169. Acesso em: 19/01/19.

CASTELLS, Manuel. La era de la información: Economía, Sociedad y Cultura. v.1 La sociedad red. Barcelona: Alianza Editorial, 1998.

CATANZARO, Gisela. La nación entre naturaleza e historia. Sobre los modos de la crítica. Buenos Aires: Fondo de Cultura Económica, 2011.

CRESPO, Regina. Revistas en América latina: proyectos literarios, políticos y culturales. México D.F.: UNAM, 2010.

Revistas culturais e literárias latinoamericanas: objetos de pesquisa, fontes de conhecimento histórico e cultural. In: JUNQUEIRA, Mary Anne; FRANCO, Stella Maris (orgs.). Cadernos de seminários de pesquisa. V. 2. São Paulo:USP/ Humanitas, 2011, p.98-116. Disponível em: http://historia.fflch.usp.br/sites/historia.fflch.usp.br/f iles/CSP2.pdf. Acesso em: 26/07/19.

EHRLICHER, Hanno; RIßLER-PIPKA, Nanette (eds.). Almacenes de un tiempo en fuga: Revistas culturales en la modernidad hispánica. Aachen, Shaker Verlag, 2014.

GRANADOS, Aimer (coord.). Las revistas en la historia intelectual de América Latina: redes, política, sociedad y cultura. Juan Pablos Editor: UAM Cuajimalpa, 2012.

MAÍZ, Claudio. Tramas culturales. De las determinaciones sociales a la red intelectual. In: Anos 90, Porto Alegre, v. 20, n. 37, p. 19-35, jul. $2013 . \quad$ Disponível em: https://seer.ufrgs.br/anos90/article/view/38431. Acesso em: 15/01/19.

La eficácia de las redes em la transferência de bienes simbólicos: el ejemplo del modernismo hispanoamericano. In: Alpha, Osorno, n.33, diciembre, 2011, p. 23-41. Disponível em: https://scielo.conicyt.cl/scielo.php?script=sci_arttex t\&pid=S071822012011000200003\&Ing=pt\&nrm=is o\&tlng=es. Acesso em: 28/03/17

Entre lo descriptivo y lo denso: publicaciones periódicas e historia literaria. In: AGUDELO OCHOA, Ana María; BEDOYA SANCHEZ, Gustavo Adolfo (orgs.). Prensa, literatura y cultura. Aproximaciones desde Argentina, Colombia, Chile y México. Lima: Centro de Estudios Literarios Antonio Cornejo Polar, 2016, p. 9-33.

MACHADO DE ASSIS, Joaquim Maria. Discurso de Encerramento do $1^{\circ}$ Ano Acadêmico da Academia Brasileira de Letras (07/12/1897). Disponível em: http://machado.mec.gov.br/obra-completalista?start=84 
MORAÑA, Mabel. Revistas culturales y mediación letrada en América Latina. In: Revista Travessia 40; outra travessia 1. Ilha de Santa Catarina $-2^{\circ}$ semestre 2003, p. 67-74. Disponível em:

https://periodicos.ufsc.br/index.php/Outra/article/downl oad/13093/12172. Acesso em: 13/01/19

PATIÑO, Roxana. Intelectuales en transición. Las revistas culturales argentinas (1981-1987). In: Cuadernos de Recienvenido $\mathrm{N}^{\circ}$ 4. Sao Paulo: Universidade de São Paulo, 1997, p. 5-34. Disponível em: http://www.ahira.com.ar/wpcontent/uploads/2018/09/Pati\%C3\%B1o-

Intelectuales-en-transici\%C3\%B3n.-Las-revistasculturales-argentinas-1981-1987.pdf.Acesso em: 20/07/19.

PITA GONZALES, Alexandra. Revistas culturales y redes intelectuales una aproximación metodológica. In: Temas de nuestra América n.54, Julio-diciembre 2013, p. 177-194. Disponível em: https://core.ac.uk/download/pdf/48874619.pdf.

Acesso em: 31/01/17.

Las Revistas Culturales Como Fuente de Estudio de Redes Intelectuales. In: DEL PALACIO, Celia; MARTINEZ MENDOZA, Sarelly (orgs.). Voces de papel. La prensa en Iberoamérica de 1792 a 1970. Colección social y humanística. Universidad Autónoma de Chiapas, 2008, p. 7585.
; BARBEITO, Ignacio; GRISENDI, Ezequiel; et al. Revistas y redes intelectuales. Ejercicios de lectura. In: Revista de Historia de América, núm. 157, julio-diciembre 2019, p. 243-270. Disponível em:

https://www.academia.edu/39539090/DOCUMENT O._Revistas_y_redes_intelectuales._Ejercicios_de lectura. Acesso em: 28/07/19.

REVISTA BRAZILEIRA. Primeiro ano, Tomo I. Laemmert \& C. Editores. Rio de Janeiro: São Paulo: 1895.

ROCCA, Pablo. Por qué para qué una revista (Sobre su naturaleza y su función en el campo cultural latinoamericano). In: SOSNOWSKI, Saul (org.). Hispamérica, Año 33, No. 99 (Dec., 2004), pp. 319.

SARLO, Beatriz. El rol de las revistas culturales. In: Espacios, núm. 12, 1993, p. XII.

Intelectuales y revistas: razones de una práctica. In: América: Cahiers du CRICCAL, n`910, 1992. Le discours culturel dans les revues latino-américaines, 1940-1970, p. 9-16. Disponível em: https://www.persee.fr/doc/ameri_09829237_1992_num_9_1_1047. Acesso em: $31 / 01 / 17$.

SOSNOWSKI, Saúl (ed.). La cultura de un siglo. América latina en sus revistas. Madrid: Buenos Aires, Alianza Editorial, 1999.

\section{COMO CITAR ESSE ARTIGO}

MAÍZ, Claudio; FONSECA, Claudia Lorena. Internacionalização de saberes e redes acadêmicas: sobre revistas e circulação das ideias na América Latina. Signo, Santa Cruz do Sul, v. 44, n. 81, dez. 2019. ISSN 1982-2014. Disponível em: $\quad<$ https://online.unisc.br/seer/index.php/signo/article/view/14008>. Acesso em: doi: https://doi.org/10.17058/signo.v44i81.14008. 